\title{
A Proposal of Spatial Indexing Algorithm for Effective Visualization of GIS Based-BIM Data
}

\author{
Ji-Eun Kim and Chang-Hee Hong
}

\begin{abstract}
The facility maintenance using BIM data reflects a need for maintenance system that considers efficient operation of administrators and managers. This system which takes advantage of the vast amount of 3D facility data is able implement the interoperate navigation and visualization. However, the quick and smooth visualization process for a large-scale BIM data is an important factor to be solves in future. The purpose of this study is to design the spatial indexing algorithm for effective visualization of BIM data based on GIS, and propose the spatial indexing method reconfigures an IFC schema structure. It is designed with the scenario of the coordinate transformation, so the implemented algorithm is verified with IFC sample data.
\end{abstract}

Index Terms-Building information modeling, geographic information system, OcTree, spatial indexing, visualization.

\section{INTRODUCTION}

Recently as rising the interest of indoor geographic information system (GIS) of facility, the researches for variety of information technology representing indoor GIS are increasing. According as the urban facility including single building is larger and more complex, a facility maintenance based on indoor GIS is required with a facility maintenance of the local unit.

Building information modeling (BIM) includes data generated by the whole life of the facility through 2D drawing process to $3 \mathrm{D}$ modelling. Through the geometry and property information of object, it can show the multiple relationships with indoor GIS. Spatially the facility maintenance using BIM data reflects a need for maintenance system that considers efficient operation of administrators and managers.

This system which takes advantage of the vast amount of 3D facility data is able implement the interoperate navigation and visualization. However, the quick and smooth visualization process for a large-scale BIM data is an important factor to be solves in future. Therefore this study would like to design the spatial indexing algorithm for effective visualization of BIM data based on GIS, and propose the spatial indexing method reconfigures an IFC schema structure.

Manuscript received May 10, 2014; revised July 20, 2014. This research was supported by a grant from a Strategic Research Project (Development of BIM/GIS Interoperability Open-Platform 2014) funded by the Korea Institute of Construction Technology.

The authors are with SOC Research of Korea Institute of Civil engineering and building Technology, Gyunggi, 411-712 Korea (e-mail: jekim@kict.re.kr, chhong@kict.re.kr).

\section{Research Process}

This study investigates and analyses the research trend related to data visualization and spatial indexing in domestic and abroad, and derives the suggestion. And the spatial indexing method which is effective for BIM data (IFC, Industry Foundation Classes) and GIS data is selected to communicate the user needs quickly and clearly, and the algorithm architecture is envisioned based on scenario for realization. Finally in order to verify the spatial indexing algorithm proposed, the test is processed with IFC sample data applying it. The research process is as follow Fig. 1.

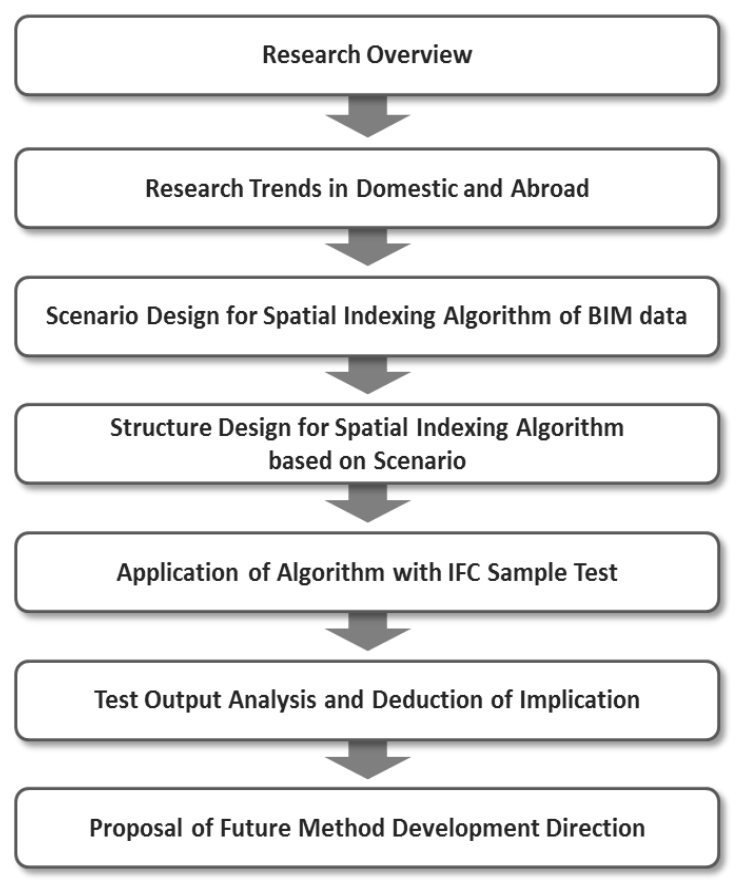

Fig. 1. Research process.

\section{Literature REVIEW}

As rising the needs for construction of indoor GIS, several studies in dealing with cooperation between BIM and GIS are ongoing. In order to solve the primary issues such as data loss and incompatibility that occurs when linking data formats and specific software, interoperability should be considered with priority. This is the basis in response to request of the user on the system, to visualize effectively geometry information of 3D building data. Among the various techniques that are using in computer graphics, this study derived the optimized method which is appropriate to BIM data structure.

This study investigated the current related research of cooperation between BIM and GIS and spatial indexing 
technique of data as Table I.

TABLE I: ADVANCED RESEARCH REVIEW [1]-[6]

\begin{tabular}{|c|c|}
\hline \multirow{2}{*}{$\begin{array}{l}\text { Research } \\
\text { Information }\end{array}$} & Research Title \\
\hline & Main Issue \\
\hline \multicolumn{2}{|c|}{ Interoperability of BIM and GIS } \\
\hline \multirow{2}{*}{$\begin{array}{l}\text { EDoo Kim, } \\
\text { et al. } \\
(2011)[1]\end{array}$} & $\begin{array}{l}\text { Constructing 3-D GIS Campus Model with Detailed B } \\
\text { uilding Information }\end{array}$ \\
\hline & $\begin{array}{l}\text { Presents a method for acquiring detailed building mod } \\
\text { els from BIM and managing the building information } \\
\text { on 3-D GIS }\end{array}$ \\
\hline \multirow{2}{*}{$\begin{array}{l}\text { Ruban de } \\
\text { Laat, } \\
\text { et al. } \\
(2010)[2]\end{array}$} & $\begin{array}{l}\text { Integration of BIM and GIS: The Development of the } \\
\text { CityGML GeoBIM Extension }\end{array}$ \\
\hline & $\begin{array}{l}\text { Describes the development of a CityGML extension ca } \\
\text { lled GeoBIM to get semantic IFC data into a GIS cont } \\
\text { ext }\end{array}$ \\
\hline \multirow{2}{*}{$\begin{array}{l}\text { TaeWook } \\
\text { Kang, } \\
\text { et al. } \\
\text { (2012)[3] }\end{array}$} & $\begin{array}{l}\text { The External BIM Reference Model Suggestion for Int } \\
\text { eroperability Between BIM and GIS }\end{array}$ \\
\hline & $\begin{array}{l}\text { Proposes the external BIM reference model including } \\
\text { the metadata which defines mapping rules from IFC to } \\
\text { CityGML }\end{array}$ \\
\hline
\end{tabular}

Spatial Partitioning Method

\begin{tabular}{c|l}
\hline \multirow{2}{*}{$\begin{array}{c}\text { SooHee } \\
\text { Han(2013)[4] }\end{array}$} & $\begin{array}{l}\text { Design of Memory-Efficient Octree to Query Large 3 } \\
\text { D Point Cloud }\end{array}$ \\
\cline { 2 - 2 } $\begin{array}{c}\text { Designs a memory-efficient octree for querying large } \\
\text { 3D point cloud }\end{array}$ \\
\hline \multirow{2}{*}{$\begin{array}{c}\text { Lee }, \\
\text { et al. }\end{array}$} & $\begin{array}{l}\text { DGR-Tree : An Efficient Index Structure for POI Sear } \\
\text { ch in Ubiquitous Location Based Services }\end{array}$ \\
\cline { 2 - 2 } $\begin{array}{c}\text { 2009)[5] } \\
\text { et al. }\end{array}$ & $\begin{array}{l}\text { Examines how to search large and skewed POI efficie } \\
\text { ntly in the u-LBS environment and proposes the Dyna } \\
\text { mic-level Grid based R-Tree }\end{array}$ \\
\hline \multirow{2}{*}{$\begin{array}{c}\text { (2010)[6] } \\
\text { ChillO Ga, }\end{array}$} & $\begin{array}{l}\text { Study on the Method to Create a Pedestrian Path Usin } \\
\text { g Space Decomposition based on Quadtree }\end{array}$ \\
\cline { 2 - 2 } & $\begin{array}{l}\text { Suggests appropriate methods to create paths that can } \\
\text { be used in pedestrian navigation service, by using mot } \\
\text { ion-planning technology }\end{array}$ \\
\hline \hline
\end{tabular}

Most of them handled the interoperability issues coming from the connection with heterogeneous software of BIM and GIS in different environments. Also the connection methods between IFC data for facility representation on GIS and geospatial information such as GML have been studying. In the case of spatial indexing, there were many researches about data processing of large-scale BIM data and visualization of geometry information. After that, main issues were confirmed as like the lightening method of large-scale BIM data and the visualization based on level of detail. This study would like to propose a spatial indexing method considering the problems mentioned above.

\section{Design OF Spatial IndeXING Algorithm}

\section{A. Algorithm Scenario}

First, this study simplified the basic IFC structure that is a standard format of BIM modeling for algorithm design. IFC Entities relating to spatial indexing and visualization were extracted and they were reconstituted as Fig. 2. The rebuilding of structure is essential due to the characteristics of IFC which contains all data generated by whole life cycle of facility. Simplification of the IFC structure has been working

with entities(IfcProject/IfcBuilding/IfcObject/IfcProduct) that are directly related to facility visualization for a large-scale data processing. The representative bottom attributes in various attributes belonged to each entity and the other properties are added for part of spatial indexing algorithm.

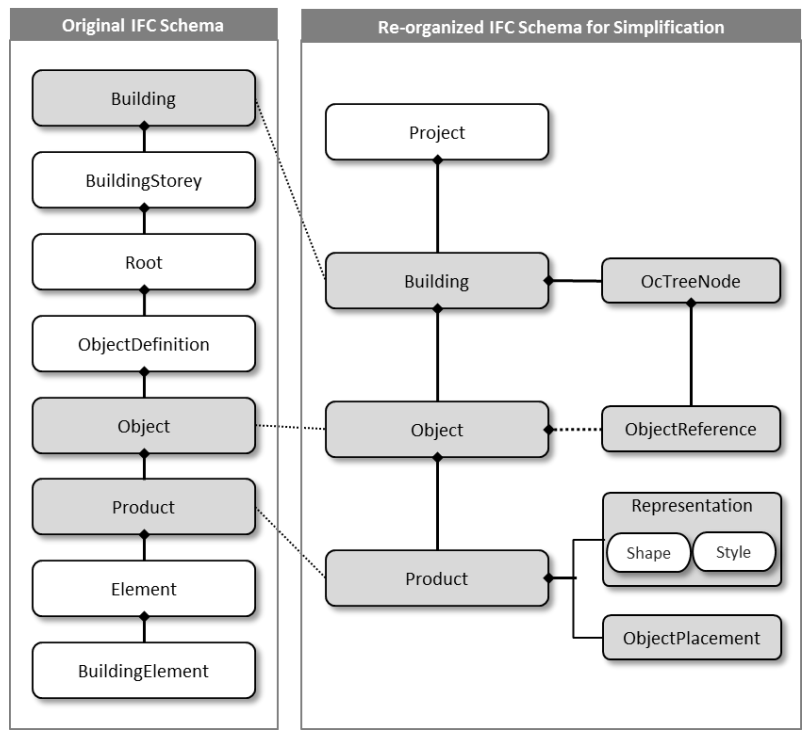

Fig. 2. Main algorithm scenario reorganizing IFC schema.

Secondly, Local coordinates entered in IFC data of facility are transported to World coordinates. In GIS map database, the representation of absolute position as like the local area for neighboring relationships is implemented using World coordinates basically. Therefore, to show the size of the object in consideration of deformation of displacement the location on the application, Local coordinates must be converted to World coordinates. Fig. 3 is the process diagram of coordinate change based on IFC schema from Local coordinates to World coordinates. Objects in BIM model are converted from each Local coordinates in entity(IfcBuilding/ IfcBuildingstorey/IfcSpace/IfcProduct) to World coordinates for showing on GIS map through the relationships(R1, R2) between objects or structures.

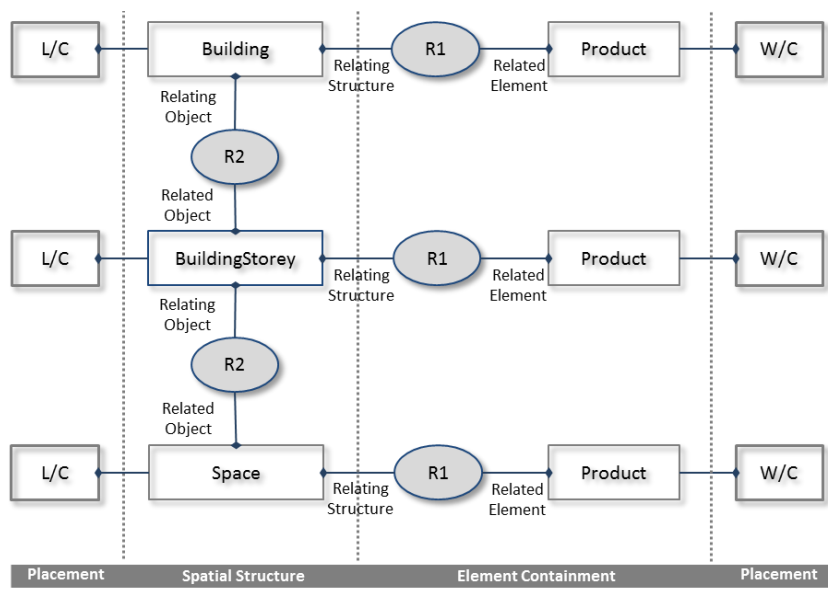

Fig. 3. Main algorithm scenario for process diagram of coordinate change. based on IFC schema. 


\section{B. Algorithm Structure}

This study takes advantage of the OcTree structure as space division technique. The OcTree is able to have Child nodes up to 8 nodes for each Parent node, which is one of the tree structure, and it is used to store a pointer in an object or determine of the dynamic visibility at the game. Child nodes organize the same size cube that is equally divided into 8 cubes with Parent cube, and they configure repeatedly until the objects in each node are in a certain number [7]. Fig. 4 is presented the OcTree partitions space with frame and color.

The algorithm structure is composed by applying the OcTree technique at the scenario with UML as shown in Fig.
5. Main structure of the algorithm is divided into Part A and $\mathrm{B}$, and each part is connected together.
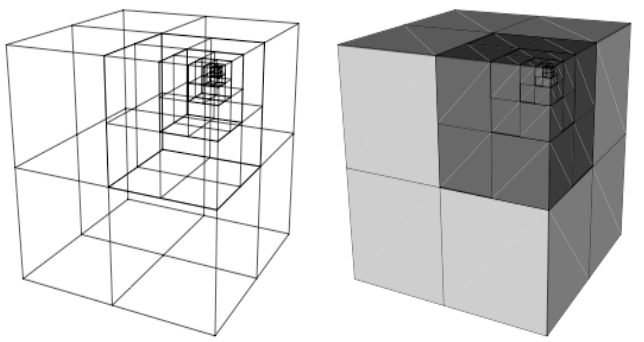

Fig. 4. Presentation of OcTree [8].

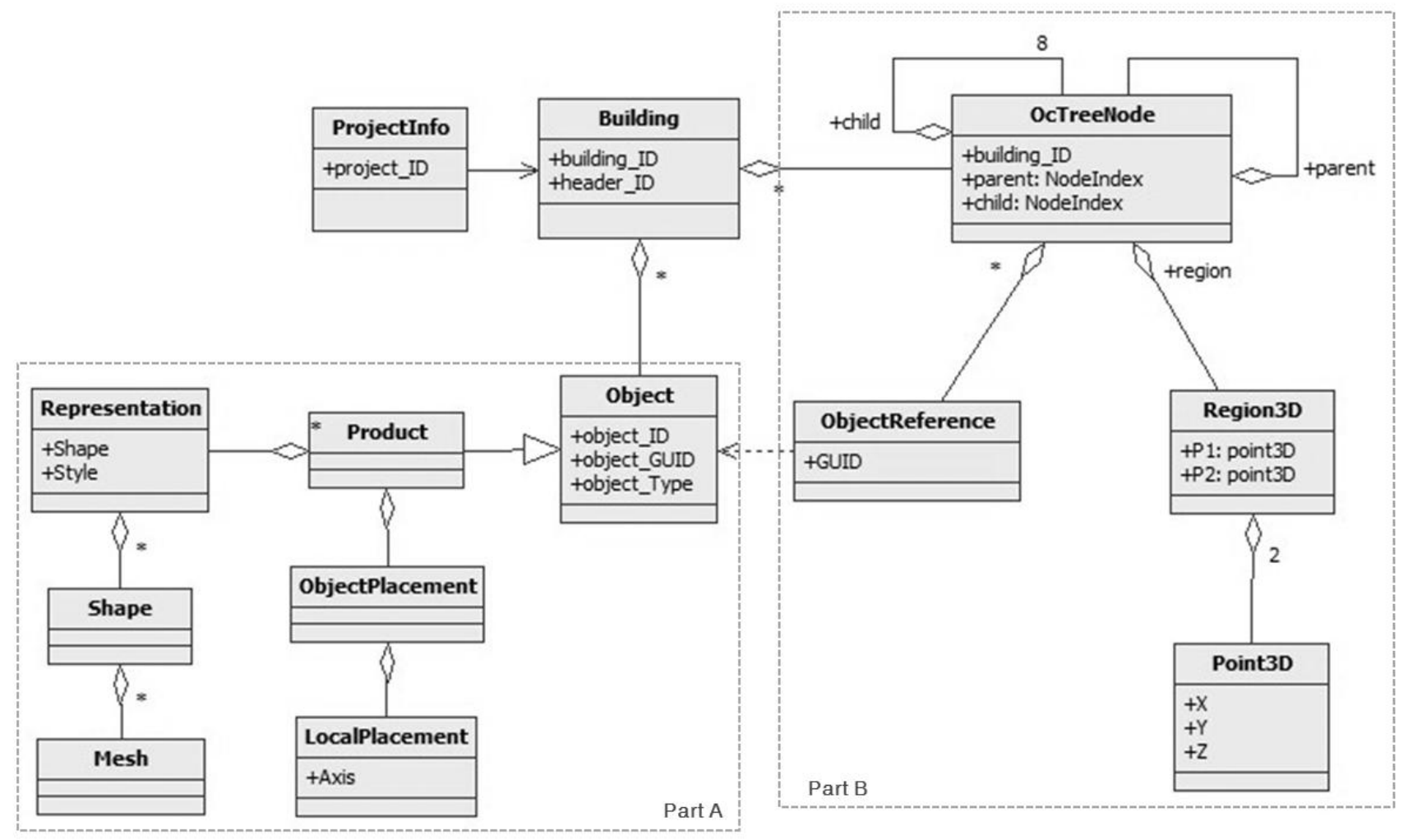

Fig. 5. Spatial indexing algorithm structure.

Part A shows to represent the geometry data using IFC structure, and it is analyzed the relationship of IFC class based on IFC data structure. The detailed structure of class is shown in Table II. Part B shows to search the IFC object using OcTree technique and visualize it. As described in Section A, after that was converted from World coordinates to Local coordinates, the algorithm can proceed the objects based on World coordinates which are converted within region through OcTree nodes with space indexing as a range of visualization. The mapping of the IFC data used the GUID of IFC object. The detailed structure of class is shown in Table II and Table III.

\section{ApPlication of Spatial IndeXING Algorithm BASED ON OCTREE}

\section{A. Architecture of Algorithm}

This study implemented an algorithm that applies the space indexing technique based on OcTree at the information of a large-scale BIM data in order to perform spatial search of facility objects. Fig. 6 describes spatial indexing structure of BIM data model based on OcTree

First of all, a bounding box surrounding the IFC data as a range of visualization is defined and it is divided at the same time based on the three axis $X, Y, Z$. The segmentation process is performed recursively with basic OcTree structure and the end condition sets up to 3 levels, the number of boxes that have been divided until 512 [9]. After the division process is completed, the algorithm contains the geometric elements in bounding box and stores index values for each object in the index buffer based on OcTree. Fig. 7 is the sequence of spatial indexing and contains pseudo code.
A: Check Frustum()
B: Get Spatial Index()
C: Get Level of Detail()
D: Return Spatial Index_Level of Detail
E: Check Cache()
F: Get Object Data()
G: Return Object Data
H: Make Request URI() 

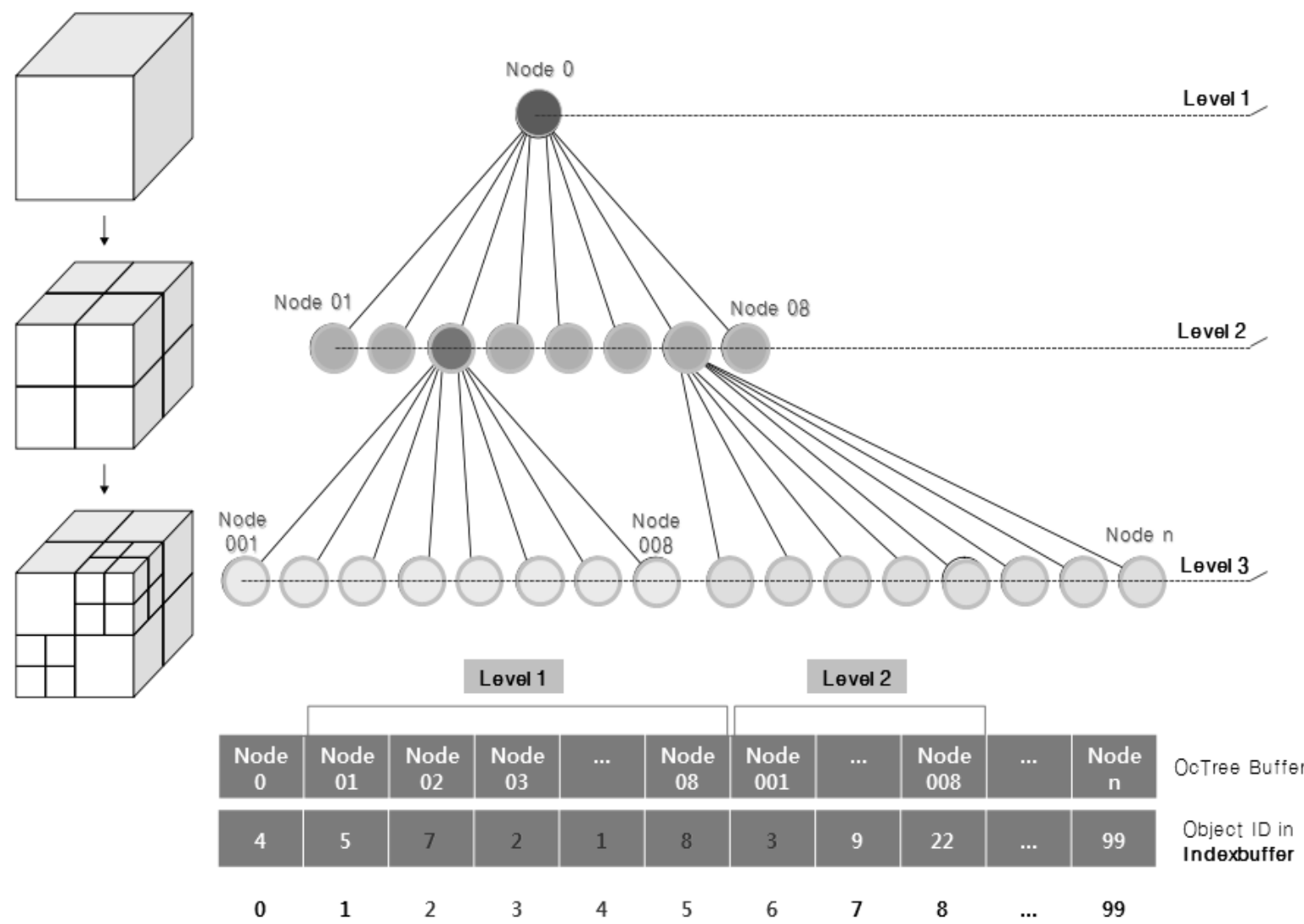

Fig. 6. Spatial indexing structure of large-scale BIM data model.

TABLE II: DESCRIPTION OF UML CLASS BASED ON IFC

\begin{tabular}{|c|c|c|}
\hline Class & Member & Description \\
\hline ProjectInfo & project_ID & $\begin{array}{l}\text { Project information including the } \\
\text { building }\end{array}$ \\
\hline \multirow{2}{*}{ Building } & building_ID & Building own ID by modeler \\
\hline & header_ID & Header own ID by modeler \\
\hline \multirow{3}{*}{ Object } & object_ID & Object own ID by modeler \\
\hline & object_GUID & $\begin{array}{l}\text { Object own GUID assigned } \\
\text { automatically in project }\end{array}$ \\
\hline & object_Type & Object type by modeler \\
\hline Product & - & Low level of object generally in IFC \\
\hline $\begin{array}{c}\text { Object } \\
\text { Placement }\end{array}$ & - & $\begin{array}{l}\text { Object placement with local } \\
\text { coordinate for relating with GIS data }\end{array}$ \\
\hline \multirow{2}{*}{ Representation } & shape & \multirow{2}{*}{$\begin{array}{l}\text { Representation of object with shape } \\
\text { and style }\end{array}$} \\
\hline & style & \\
\hline Shape & - & Shape of object \\
\hline Mesh & - & Shape type for visualization \\
\hline
\end{tabular}

This algorithm implemented with World Wind Java in consideration of the expansion with GIS in the future and it is set to visualize the BIM data on the web. In the case of accessing to visualize the 3D facility model, after searching the nodes in the box which is included in field-of-view considered user point, by rendering first the objects contained in the box, it can be visualized efficiently a large-scale data.

TABLE III: DESCRIPTION OF UML CLASS BASED ON OCTREE

\begin{tabular}{|c|c|c|}
\hline Class & Member & Description \\
\hline \multirow{3}{*}{ OcTreeNode } & building_ID & $\begin{array}{c}\text { Building own ID by modeler for } \\
\text { mapping }\end{array}$ \\
\hline & parent: NodeIndex & Parent node for spatial indexing \\
\hline & child: NodeIndex & Child node for spatial indexing \\
\hline $\begin{array}{c}\text { Object } \\
\text { Reference }\end{array}$ & GUID & $\begin{array}{l}\text { Relationship point between } \\
\text { object and OcTreeNode }\end{array}$ \\
\hline \multirow{2}{*}{ Region3D } & $P_{1}:$ point $3 \mathrm{D}$ & Point 1 of Spatial Indexing Area \\
\hline & $P_{2}:$ point $3 \mathrm{D}$ & Point 2 of Spatial Indexing Area \\
\hline \multirow{3}{*}{ Point3D } & $X$ & $X$ axis for $3 \mathrm{D}$ \\
\hline & $Y$ & $Y$ axis for $3 \mathrm{D}$ \\
\hline & $Z$ & $Z$ axis for $3 \mathrm{D}$ \\
\hline
\end{tabular}

\section{B. Application and Test Results}

The test was conducted with IFC sample data for verification of the algorithm of spatial indexing based on OcTree. Sample model is made up of university building with 5 levels and it is constructed 1268 objects, 63 space, 4143.9 $\mathrm{m}^{2}$ scale and 30017 TIN structures. This is shown in Fig. 8. In 
order to test for verification, this study made building visualize based on sample data and performed space division, which set the path to pass through it (Fig. 9).

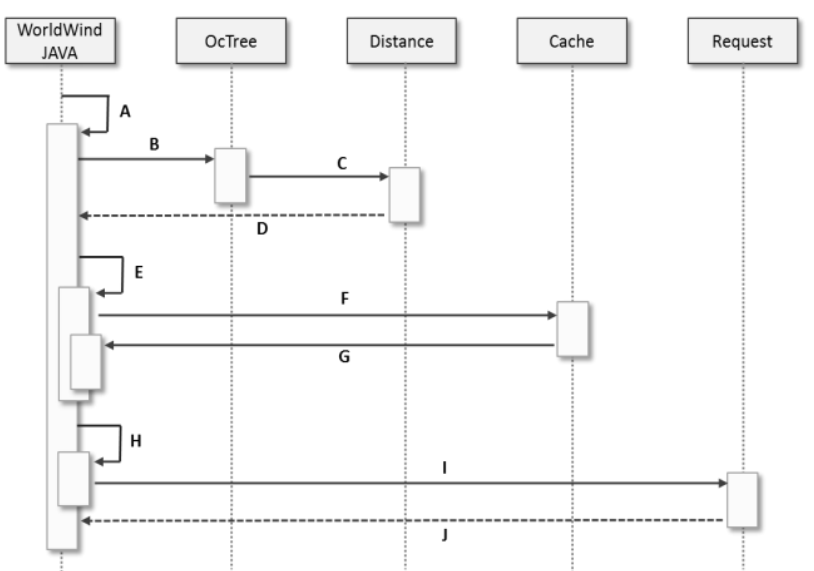

Fig. 7. Sequence of spatial indexing.

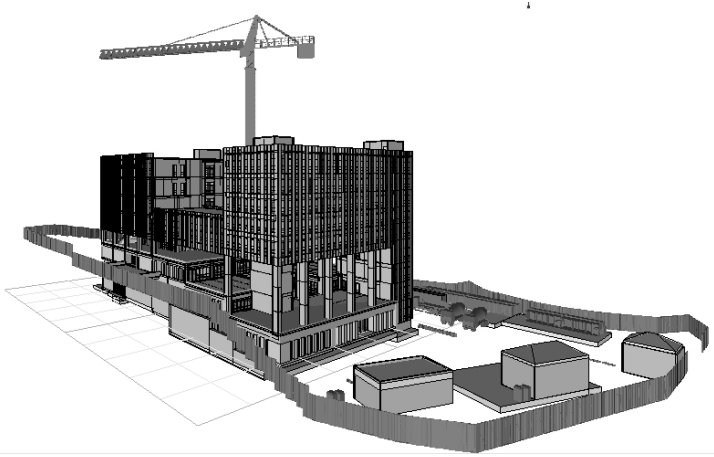

Fig. 8. IFC sample data for algorithm test.
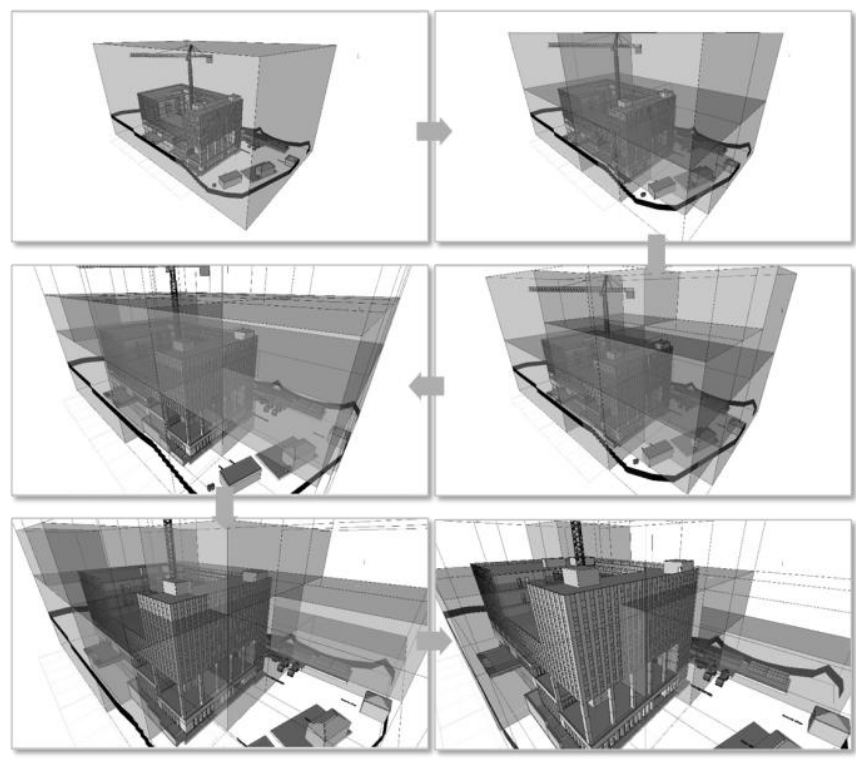

Fig. 9. Spatial indexing test of the pass through the building.

The frame rate was measured at 5 second intervals for applying the spatial indexing algorithm based on OcTree and non-applying while the view of user point was passing by the path. Fig. 10 is a graph comparing the results of applying the algorithm of the spatial indexing. The rendering time is measured in hertz of number of frames per second. And including about 6 frames per second what user can feel interaction, the user can react and immerse in response the screen providing real-time information about 15 frames [10].
The results of the test, the number of frames applying the algorithm was higher than non-applying case from 3 frames to 14 frames per second. This could be made to reduce the rate for visualizing data to user and improve accessibility. To ensure the verification results more objective, the evaluation for visualization and procedure of many other BIM data is required in the future.

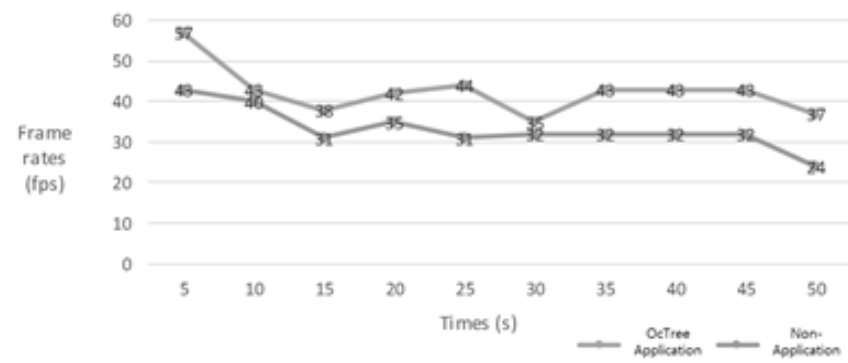

Fig. 10. Comparison on frame rates of spatial indexing method application for OcTree-based BIM data.

\section{CONCLUSION}

This study has proposed the spatial indexing algorithm for effective visualization of BIM data based on GIS. After investigating and analyzing research trends of spatial indexing, the implications were derived. Based on this, the structure of IFC data schema was reconstructed and simplified. Also the spatial indexing algorithm of BIM data was designed with the scenario of the coordinate transformation, and the implemented algorithm was verified with IFC sample data.

The spatial indexing algorithm reconstituted the bounding volume of building in the structure based on OcTree. It improves the visualization speed by searching and rendering the objects that are contained in the viewing space at the time of approaching close to the building. In future, the algorithm would be applied and analyzed to other BIM data, then developed with relating the LOD according to visualization.

\section{ACKNOWLEDGMENT}

This research was supported by a grant from a Strategic Research Project (Development of BIM/GIS Interoperability Open-Platform 2014) funded by the Korea Institute of Construction Technology.

\section{REFERENCES}

[1] E. D. Kim and I. D. Go, "Constructing 3-D GIS campus model with detailed building information," Journal of Urban Design Institute of Korea, vol. 12, no. 3, pp.15-26, June, 2011.

[2] R. D. Laat and L. V. Berlo, "Integration of BIM and GIS: the development of the CityGML GeoBIM extension," in Proc. The 3D Geo-Information Sciences, pp.211-225, 2011.

[3] T. W. Kang, C. H. Hong, J. R. Hwang, and H. S. Choi, "The external BIM reference model suggestion for interoperability between BIM and GIS," Journal of Korea Spatial Information Society, vol. 20, no. 5, pp.91-98, 2012.

[4] S. H. Han, "Design of memory-efficient octree to query large 3D point cloud," Journal of Korea Society of Surveying, Geodesy, Photogrammetry and Cartography, vol. 31, no. 1, pp.41-48, 2013.

[5] D. W. Lee, H. K. Hong, K. Y. Lee, and K. J. Han, "DGR-tree : an efficient index structure for POI search in ubiquitous location based services," Journal of Korea Spatial Information Society, vol. 11, no. 3, pp. 55-62, 2009. 
[6] C. O. Ga, H. S. Woo and K. Y. Yu, "Study on the method to create a pedestrian path using space decomposition based on quadtree," Journal of Korea Spatial Information Society, vol. 18, no. 4, pp. 89-98, 2010.

[7] Y. M. Kim, "A Greed space partitioning method using leaf nodes of QuadTree on MMORPG," M.S. thesis, Chungnang University, Korea, 2004.

[8] J. Braun, C. Thieulot, P. Fullsack, M. DeKool, C. Beaumont, and R. Huismans, "DOUAR: a new three-dimensional creeping flow model for the solution of geological problems," Journal of Physics of the Earth and Planetary Interiors, vol. 171, pp. 76-91, 2008.

[9] White Timberwolf, Schematic Drawing of an OcTree. [Online] Available: http://commons.wikimedia.org/wiki/

[10] A. Moller, Real-Time Rendering, $2^{\text {nd }}$ edition, AK Peters. 2002.

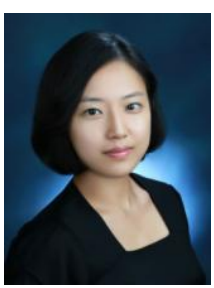

Ji-Eun Kim was born in 1985 and she lives in Seoul Korea. She has received her master's degree in digital architecture (building information modeling) from the University of Kyung Hee in 2012. She worked as a researcher at Korea Research Institute for Human Settlements (2012 2013) and she is currently works as a researcher at ICT Convergence and Integration Research Division, Korea Institute of Civil Engineering and building Technology.

Ms. Kim is involved in some practical project like "Development of BIM/GIS interoperability open-platform", "Development of integrated operation technology on construction information \& spatial information based on BIM/GIS interoperation platform" and "architectural MEP object reverse engineering technology development for the facility management".

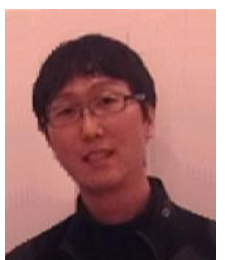

Chang-Hee Hong has received his master's degree in civil engineering from Inha University in 1999. He has completed his $\mathrm{PhD}$ from Graduate School of Environmental Studies, Seoul National University in 2006. He works currently as a senior researcher, ICT Convergence and Integration Research Division, Korea Institute of Civil Engineering and building Technology since 1999

His majors and interests include BIM/GIS interoperability, construction and ICT convergence, remote sensing, geographic information system. 